\title{
Importance of severity of coronary artery disease for the tolerance to normovolemic hemodilution
}

\author{
Comparison of single-vessel versus multivessel stenoses in a canine \\ model
}

The response of global cardiovascular and regional myocardial function (as seen with sonomicrometry) to continuous, progressive hemodilution (Dextran 70) was compared in dogs with proximal circumflex coronary artery stenosis and dogs with proximal circumflex coronary artery and proximal left anterior descending artery stenoses. Hemodilution-induced failure, defined as greater than $\mathbf{5 0} \%$ loss in function or death of the animal, was determined for systolic shortening in the circumflex coronary artery and left anterior descending artery territories, mean arterial pressure, and maximum left ventricular rate of pressure rise. Time to failure was compared between groups by log-rank tests. Systolic shortening of the circumflex coronary artery failed at a similar median time point in both groups ( 30 minutes in the group with single-vessel stenosis and hemodilution versus $\mathbf{4 0}$ minutes in the group with multivessel stenosis and hemodilution). Systolic shortening of the left anterior descending artery (80 versus 50 minutes), mean arterial pressure ( 70 versus 50 minutes), and maximum left ventricular rate of pressure rise ( 70 versus 40 minutes), however, failed significantly later $(p<0.01)$ in animals with single circumflex coronary artery stenosis. A marked increase $(+50 \%)$ in systolic shortening of the left anterior descending artery was observed during hemodilution only in the circumflex coronary artery stenosis group. The better hemodilution tolerance in the circumflex coronary artery stenosis group may be explained by the compensatory increase in myocardial contractile function in non-coronary flowcompromised myocardium, which seems to be crucial for global cardiovascular stability during hemodilution in the presence of coronary stenoses. (J Thorac Cardiovasc Surg 1994;108:231-9)

Donat R. Spahn, MD, L. Richard Smith, PhD, ${ }^{b}$ Randall M. Schell, MD, ${ }^{a}$

Robert D. Hoffman, BS, ${ }^{a}$ Richard Gillespie, BS, ${ }^{a}$ and Bruce J. Leone, MD, ${ }^{a}$ Durham, N.C.

\footnotetext{
A

cute normovolemic hemodilution is well tolerated in canine models of single vessel coronary artery disease, as evidenced by stable global cardiovascular function and well maintained regional myocardial contractile functions in the left ventricular (LV) myocardium supplied by

From the Division of Cardiac Anesthesia, Department of Anesthesiology, The Heart Center at Duke University, and the Division of Biometry, Department of Community and Family Medicine, Duke University Medical Center, ${ }^{b}$ Durham, N.C.

Received for publication Oct. 1, 1993.

Accepted for publication Jan. 3, 1994.

Address for reprints: Bruce J. Leone, MD, Department of Anesthesiology, Duke University Medical Center, P.O. Box 3094, Durham, NC 27710

Copyright 1994 by Mosby-Year Book, Inc.

$0022-5223 / 94 \$ 3.00+0 \quad \mathbf{1 2} / \mathbf{1} / \mathbf{5 4 0 7 5}$
}

the critically constricted coronary artery. ${ }^{1,2}$ However, little is known regarding hemodilution tolerance in the presence of multivessel coronary artery disease. The present study therefore was designed to compare the responses of global cardiovascular and regional myocardial functions to acute normovolemic hemodilution in a canine model of single versus multivessel coronary artery disease.

\section{Methods}

This study was approved by the Institutional Animal Care and Use Committee, and all animals used in these experiments received humane care in compliance with the "Principles of Laboratory Animal Care" formulated by the National Society for Medical Research and the "Guide for the Care and Use of Laboratory Animals" prepared by the Institute of Laboratory Animal Resources and published by the National Institutes of Health (NIH Publication No. 86-23, revised 1985).

Instrumentation. In 45 unpremedicated dogs, weighing 18 to 
$22 \mathrm{~kg}$, anesthesia was induced with thiopental sodium ( 20 to 25 $\mathrm{mg} / \mathrm{kg}$ intravenously). The trachea was intubated, and the animals' lungs were ventilated with an air-oxygen mixture to normocarbia at a rate of 10 breaths/min (Ohio V5 Airco; Ohmeda, Madison Wis.) to achieve an arterial oxygen partial pressure of 150 to $200 \mathrm{~mm} \mathrm{Hg}$. End-tidal carbon dioxide and halothane concentrations were continuously measured by infrared spectroscopy (Datex model 254; Puritan Bennett Corporation, Wilmington, Mass.). During the surgical preparations, anesthesia was maintained with halothane $1.5 \%$ to $2.0 \%$ (end-tidal). The animals were placed in a right lateral position, and an intravenous cannula was introduced in the hind limb through which a continuous infusion of $0.9 \%$ saline solution ( 5 to 7 $\mathrm{ml} \cdot \mathrm{kg}^{-1} \cdot \mathrm{hr}^{-1}$ ) was maintained. A $7 \mathrm{~F}$ pressure-transducertipped catheter (Millar Instruments, Inc., Houston, Tex.) was inserted in the carotid artery and advanced to the aortic root, within $1 \mathrm{~cm}$ of the aortic valve, to obtain aortic pressure and arterial blood gas analyses. A second arterial catheter was inserted into the right femoral artery for later blood withdrawal during hemodilution.

The heart was exposed through a left thoracotomy and suspended in a pericardial cradle; $5 \mathrm{~F}$ pressure-transducer-tipped catheters (Millar Instruments) were inserted in the right ventricle (RV) and LV. Proximal segments of the left anterior descending coronary artery (LAD), as well as the circumflex coronary artery (LC), were dissected free, and $10 \mathrm{MHz}$ Doppler flow probes were placed around the coronary vessels. LAD and LC blood flow velocities were measured with Doppler flowmeters (Model 100-1000-10; Triton Technologies, Inc., San Diego, Calif.). Additionally, two suture strings were placed around each coronary vessel: one to gradually constrict the coronary vessel with a micrometer-controlled spring-suspended constrictor, the second to briefly occlude the vessel totally for 10 seconds to assess the degree of coronary constriction. ${ }^{2}$

Three pairs of ultrasonic crystals (diameter 1.5 to $2 \mathrm{~mm}$ ), oriented in the short axis of the heart, were placed (1) in the LV subendocardium of the anterior apical region of the heart in the territory supplied by the LAD; (2) in the subendocardium of the posterior LV wall supplied by the LC, approximately on the same circumferencial plane as the LAD crystal pair; and (3) in the anterior $\mathrm{RV}$ free wall at the transition of inflow and outflow tract. The regional myocardial contraction pattern was assessed by continuously measuring the segment length between the two sonomicrometer crystals on the basis of the measurement of ultrasonic transit time (Sonomicrometer; model 120; Triton Technologies, Inc., San Diego, Calif.). ${ }^{3,4}$ The correct placement of the LAD and LC territory crystals within the area of ischemia was confirmed by observing regional function during a brief coronary occlusion. The occurrence of an ischemic contraction pattern confirmed not only proper crystal placement in the LAD or LC territory but also the absence of significant collateralization. ${ }^{5}$ Arterial hemoglobin concentration was determined with a CO-oximeter specifically calibrated for canine hemoglobin (IL482; Instrumentation Laboratory, Lexington, Mass.).

Experimental protocol. The dogs were randomly assigned to three experimental groups: in 15 animals, critical coronary stenoses were imposed on the LAD and LC, but no hemodilution was performed ( $2 \mathrm{~V}$-C group). These animals served as time controls to establish the stability of the dual coronary stenosesopen chest model over time. In 15 animals a critical stenosis was only imposed on the LC, and thereafter these animals underwent the continuous hemodilution protocol (IV-HD group). In the third group of 15 dogs, coronary stenoses were imposed on both the LAD and the LC, and subsequently the animals underwent the hemodilution protocol (2V-HD group).

After completion of the surgical preparations, halothane was adjusted to $0.9 \%$ end-tidal concentration. Baseline measurements were recorded after a stabilization period of approximately 30 to 45 minutes. Critical constrictions of the LAD and LC were then imposed according to the experimental group assignment by slowly tightening a micrometer-controlled snare to the point where the hyperemic response to a 10-second total coronary occlusion was totally abolished, yet no dysfunction occurred in the territory supplied by the LAD. ${ }^{6}$ The sequence of LAD and LC constrictions was randomized in dogs with critical constrictions imposed on both major LV coronary arteries ( $2 \mathrm{~V}-\mathrm{C}$ and $2 \mathrm{~V}-\mathrm{HD}$ groups). Data were again recorded after imposing the coronary constrictions (critical constriction).

After critical constriction data were recorded, a 2-hour protocol of continuous hemodilution was begun by simultaneously exchanging blood with $6 \%$ Dextran 70 (in $0.9 \%$ sodium chloride) (Abbott Laboratories, North Chicago, Ill.) with the use of a programmable infusion-withdrawal pump (Gemini PC-2; Imed, San Diego, Calif.). Arterial blood thereby was withdrawn at a rate of $1000 \mathrm{ml} / \mathrm{hr}$ and replaced with Dextran at a rate of $900 \mathrm{ml} / \mathrm{hr}$. We previously found that this exchange ratio results in isovolemia during hemodilution. ${ }^{2}$ Global cardiovascular and regional $R V$ and $L V$ myocardial functions, as well as arterial hemoglobin concentration, were recorded every 10 minutes during the continuous hemodilution procedure. The hemodilution procedure was stopped when the animal died or at 120 minutes of continuous hemodilution.

Data processing and calculations. The pressure signals were amplified by a low-noise direct current pre-amplifier (Grass Instruments, Quincy, Mass.), digitally converted (analog-digital converter, model 16AF; MetraByte Corporation, Taunton, Mass.), and recorded with a personal computer at a sampling rate of $500 \mathrm{~Hz}$ over a period of 5 seconds during a brief period of apnea (less than 10 seconds).

Coronary perfusion pressure was calculated as the difference between diastolic pressure measured in the aortic root and LVEDP. LV rate of pressure rise, the first derivative of $L V$ pressure with respect to time, was determined as the instantaneous slope of the LV pressure-time curve. RV rate of pressure rise was determined accordingly by means of the RV pressure curve. End-diastole was defined by the first consistent positive deflection of $\mathrm{LV}$ rate of pressure rise, and end-systole by maximum negative LV rate of pressure rise. End-diastolic segment length and end-systolic length were determined by means of the previously mentioned definitions for end-diastole and endsystole. Systolic shortening was calculated according to standard formulas. ${ }^{2}$

Data analysis and statistics. Because of a variation in coronary anatomy (big intermediate coronary artery, $n=1$ ), ongoing blood loss $(n=1)$, and arrhythmias (atrial fibrillation, $n=2$; ventricular ectopies, $n=1$ ), five animals could not be studied. Data analysis is therefore based on 12 control animals, 13 animals in the IV-HD group, and 15 animals in the $2 \mathrm{~V}-\mathrm{HD}$ group.

Hemodilution-induced failure was defined as a greater than $50 \%$ decrement in the variable examined, as compared with its value at critical constriction, or death of the animal. Failure was determined for systolic segment shortening in the LC territory, systolic segment shortening in the LAD territory, mean arterial 
Table I. Coronary flow and regional myocardial function at baseline and critical constriction

\begin{tabular}{|c|c|c|c|c|c|c|}
\hline & \multicolumn{3}{|c|}{ Baseline } & \multicolumn{3}{|c|}{ Critical constriction } \\
\hline & $2 V \cdot C$ & $I V-H D$ & $2 V-H D$ & $2 V-C$ & $I V-H D$ & $2 V-H D$ \\
\hline CF LAD $\left(\mathrm{ml} \cdot \mathrm{sec}^{-1}\right)$ & $0.52 \pm 0.06^{*}$ & $0.37 \pm 0.07$ & $0.29 \pm 0.03$ & $0.42 \pm 0.06 \dagger$ & $0.35 \pm 0.06$ & $0.23 \pm 0.02 \dagger$ \\
\hline $\mathrm{CF} \mathrm{LC}\left(\mathrm{ml} \cdot \mathrm{sec}^{-1}\right)$ & $0.66 \pm 0.09$ & $0.45 \pm 0.05$ & $0.52 \pm 0.04$ & $0.56 \pm 0.08 \dagger$ & $0.37 \pm 0.04 \ddagger$ & $0.43 \pm 0.03 \dagger$ \\
\hline EDL LAD $(\mathrm{mm})$ & $11.7 \pm 0.6$ & $12.0 \pm 0.8$ & $12.0 \pm 0.8$ & $11.8 \pm 0.6$ & $11.9 \pm 0.8$ & $11.5 \pm 0.8 \dagger$ \\
\hline EDL LC $(\mathrm{mm})$ & $10.3 \pm 0.6 \S$ & $13.0 \pm 0.7$ & $12.3 \pm 0.7$ & $10.3 \pm 0.6$ & $12.9 \pm 0.7$ & $12.3 \pm 0.7$ \\
\hline EDL RV (mm) & $10.5 \pm 0.9$ & $8.6 \pm 0.6$ & $10.8 \pm 0.9$ & $10.7 \pm 1.0$ & $8.5 \pm 0.5$ & $10.4 \pm 0.9 \dagger$ \\
\hline SS LAD $(\%)$ & $19.2 \pm 1.1$ & $22.1 \pm 2.8$ & $23.6 \pm 1.8$ & $18.2 \pm 1.2$ & $21.4 \pm 2.9$ & $23.3 \pm 1.8$ \\
\hline SS LC $(\%)$ & $12.8 \pm 0.8$ & $13.0 \pm 1.3$ & $11.9 \pm 1.1$ & $11.3 \pm 0.9 \dagger$ & $12.7 \pm 1.2$ & $12.0 \pm 1.0$ \\
\hline SS RV $(\%)$ & $15.2 \pm 2.1$ & $15.3 \pm 1.7$ & $15.7 \pm 1.8$ & $14.6 \pm 2.2$ & $14.6 \pm 1.6$ & $14.3 \pm 1.8$ \\
\hline
\end{tabular}

Values are mean \pm standard error of the mean. $C F$, Coronary flow; $E D L$, end-diastolic segment length; $S S$, systolic shortening.

*Significant difference $(p<0.05)$ versus 2 V-HD group

+ Significant difference $(p<0.05)$ versus baseline.

$\$$ Significant difference $(p<0.01)$ versus baseline.

$\S$ Significant difference $(p<0.05)$ versus $1 \mathrm{~V}-\mathrm{HD}$ and $2 \mathrm{~V}$-HD groups.

pressure, and maximum positive $\mathrm{LV}$ rate of pressure rise. The time period for achieving a failure criterion was compared among groups by log-rank tests $(p<0.05)$. Data at baseline and critical constriction were compared by analysis of variance and the responses to progressive hemodilution (time 0 to $120 \mathrm{~min}$ utes) were compared by repeated measures analysis of variance.

An exponential curve was individually fit to the observed hemoglobin value versus time (0 to 60 minutes), and the decay constants were then compared by analysis of variance between the two hemodiluted groups to test whether both hemodiluted groups experienced a similar decrease in arterial hemoglobin value over time.

To characterize the individual responses of global cardiovascular and regional myocardial functions to progressive hemodilution, we also expressed parameters as percentage of the respective value after imposing critical constrictions. In animals that died before 120 minutes of hemodilution, missing observations at the later time points were substituted with a zero value. An independent repeated measure analysis of variance was performed on this data set to compare the responses of the observed parameters to continuous, progressive hemodilution. Data are presented as mean \pm standard error of the mean.

\section{Results}

Baseline. All global cardiovascular and all regional myocardial function parameters were similar in the two groups undergoing continuous hemodilution (Tables I and II). The control animals differed only slightly from the animals undergoing hemodilution: LAD coronary blood flow was higher than in the 2V-HD group; LV end-diastolic pressure and maximum negative $L V$ rate of pressure rise were higher and end-diastolic segment length in the LC territory was lower than in the $1 \mathrm{~V}$-HD and 2V-HD groups (Tables I and II).

Baseline versus critical constriction. Coronary constriction decreased coronary blood flow similarly in all groups and all affected vessels by approximately $15 \%$ to $20 \%$ (Table I). Regional myocardial function was largely unchanged by critical coronary constriction; only sys- tolic segment shortening in the LC territory was slightly reduced by approximately $10 \%$ in control animals (Table I). In the 2V-HD group, end-diastolic segment lengths were reduced after critical constriction in the LAD territory and in the RV free wall. Global cardiovascular function was also minimally affected by imposing critical coronary stenoses; only heart rate decreased slightly in the $1 \mathrm{~V}-\mathrm{HD}$ and $2 \mathrm{~V}-\mathrm{HD}$ groups and maximum negative LV rate of pressure rise was minimally depressed in the IV-HD group (Table II).

Effects of hemodilution on hemoglobin, global cardiovascular, and regional myocardial functions

Decrease in arterial hemoglobin. Arterial hemoglobin levels decreased similarly in both hemodiluted groups as evidenced by (1) similar decay constants (IV-HD: $-0.0146 \pm 0.0 .0001 \mathrm{~min}^{-1} ; 2 \mathrm{~V}-\mathrm{HD}:-0.0142 \pm 0.0001$ $\mathrm{min}^{-1}$ ) and (2) similar hemoglobin values measured at 30 minutes and 60 minutes of hemodilution (30 minutes: 1V-HD, $8.8 \pm 0.2 \mathrm{gm} / \mathrm{dl}, n=13 ; 2 \mathrm{~V}-\mathrm{HD}, 9.0 \pm 0.3$ $\mathrm{gm} / \mathrm{dl}, n=15 ; 60$ minutes: $1 \mathrm{~V}-\mathrm{HD}, 5.9 \pm 0.2 \mathrm{gm} / \mathrm{dl}$, $n=13 ; 2 \mathrm{~V}-\mathrm{HD}, 6.4 \pm 0.4 \mathrm{gm} / \mathrm{dl}, n=10$ ).

Time to failure. No control animal reached the failure criteria during the 120-minute observation period in any parameter. Time to failure of systolic segment shortening in the LC territory was similar in the $1 \mathrm{~V}-\mathrm{HD}$ and $2 \mathrm{~V}-\mathrm{HD}$ groups (Fig 1, $A$, Table III). As expected, time to failure in the LAD territory was markedly longer in the $1 \mathrm{~V}-\mathrm{HD}$ group as compared with that of the $2 \mathrm{~V}$-HD group (Fig. $1, B$, Table III). Times to failure of mean arterial pressure and maximum positive $L V$ rate of pressure rise were also significantly longer in the $1 \mathrm{~V}$-HD group as compared with those in the 2V-HD group (Fig. 2, $A$ and $B$, Table III).

Responses of coronary flow and regional myocardial function to continuous hemodilution. In both groups, LC 
Table II. Global cardiovascular function at baseline and critical constriction

\begin{tabular}{|c|c|c|c|c|c|c|}
\hline & \multicolumn{3}{|c|}{ Baseline } & \multicolumn{3}{|c|}{ Critical constriction } \\
\hline & $2 \mathrm{~V}-\mathrm{C}$ & $I V-H D$ & $2 V-H D$ & $2 \mathrm{~V}-\mathrm{C}$ & $I V-H D$ & $2 V-H D$ \\
\hline $\mathrm{Hb}(\mathrm{gm} / \mathrm{dl})$ & $13.9 \pm 0.3$ & $13.6 \pm 0.4$ & $13.8 \pm 0.2$ & $14.4 \pm 0.3^{*}$ & $13.9 \pm 0.3$ & $14.0 \pm 0.3$ \\
\hline HR (beats/min) & $121 \pm 4$ & $110 \pm 3$ & $109 \pm 4$ & $121 \pm 4$ & $107 \pm 3^{*}$ & $102 \pm 3 \dagger$ \\
\hline LVEDP (mm Hg) & $10.7 \pm 1.5 \ddagger$ & $6.7 \pm 1.5$ & $6.1 \pm 0.8$ & $10.0 \pm 1.7$ & $6.0 \pm 1.4$ & $5.1 \pm 0.7^{*}$ \\
\hline RVEDP (mm Hg) & $3.3 \pm 0.6$ & $1.0 \pm 0.7$ & $3.4 \pm 1.0$ & $3.4 \pm 0.6$ & $0.5 \pm 0.5$ & $1.9 \pm 0.5$ \\
\hline MAP $(\mathrm{mm} \mathrm{Hg})$ & $93.7 \pm 2.4$ & $93.0 \pm 3.3$ & $86.8 \pm 3.8$ & $92.0 \pm 2.5$ & $93.2 \pm 3.7$ & $85.9 \pm 3.9$ \\
\hline $\mathrm{CPP}(\mathrm{mm} \mathrm{Hg})$ & $74.4 \pm 4.4$ & $75.4 \pm 3.4$ & $70.0 \pm 3.8$ & $74.2 \pm 4.0$ & $76.3 \pm 3.5$ & $69.6 \pm 4.1$ \\
\hline $\mathrm{LV} \mathrm{dP} / \mathrm{dtmax}\left(\mathrm{mm} \mathrm{Hg} \cdot \mathrm{sec}^{-1}\right)$ & $1211 \pm 48$ & $1135 \pm 53$ & $1159 \pm 61$ & $1244 \pm 76$ & $1116 \pm 52$ & $1122 \pm 48$ \\
\hline $\mathrm{LV} \mathrm{dP} / \mathrm{dtmin}\left(\mathrm{mm} \mathrm{Hg} \cdot \mathrm{sec}^{-1}\right)$ & $-1241 \pm 48 \ddagger$ & $-1101 \pm 47$ & $-1036 \pm 42$ & $-1243 \pm 51$ & $-1057 \pm 46 \dagger$ & $-1007 \pm 44$ \\
\hline $\mathrm{RV} \mathrm{dP} / \mathrm{dtmax}\left(\mathrm{mm} \mathrm{Hg} \cdot \mathrm{sec}^{-1}\right)$ & $265 \pm 9$ & $224 \pm 13$ & $264 \pm 21$ & $270 \pm 14$ & $221 \pm 13$ & $246 \pm 13$ \\
\hline $\mathrm{RV} \mathrm{dP} / \mathrm{dtmin}\left(\mathrm{mm} \mathrm{Hg} \cdot \mathrm{sec}^{-1}\right)$ & $-240 \pm 19$ & $-215 \pm 16$ & $-204 \pm 13$ & $-251 \pm 22$ & $-213 \pm 14$ & $-198 \pm 10$ \\
\hline
\end{tabular}

Values are mean \pm standard error of the mean. $H b$, Arterial hemoglobin; $H R$, heart rate; $L V E D P, \mathrm{LV}$ end-diastolic pressure; $R V E D P, \mathrm{RV}$ end-diastolic pressure; $M A P$, mean arterial pressure; $C P P$, coronary perfusion pressure; $\mathrm{dP} / \mathrm{dt}$, rate of pressure rise; $\max$, maximum; min, minimum.

*Significant difference $(p<0.05)$ versus $\mathrm{V}$-HD and $2 \mathrm{~V}$-HD groups.

$†$ Significant difference $(p<0.05)$ versus baseline.

$\ddagger$ Significant difference $(p<0.01)$ versus baseline.

Table III. Time to failure in animals in the $2 V$-C group and in both hemodiluted groups

\begin{tabular}{llll}
\hline Failure criteria & $2 V-C$ & $1 V-H D(m i n)^{*}$ & $2 V-H D(m i n)^{*}$ \\
\hline SS LC & None & $30(20,40)$ & $40(30,60)$ \\
SS LAD & None & $80(70,120)$ & $50(30,60) \dagger$ \\
MAP & None & $70(60,80)$ & $50(40,60) \dagger$ \\
Pos. LV dP/dt max & None & $70(60,100)$ & $40(30,60) \dagger$ \\
\hline
\end{tabular}

Values are medians with lower and upper quartiles. Failure was defined as a greater than $50 \%$ loss in function or death of the animal for systolic segment shortening in the LC and LAD territories, mean arterial pressure (MAP) and maximum positive LV rate of pressure rise. SS, Systolic shortening; MAP, mean arterial pressure; Pos. $L V d P / d t$ max, maximum positive $L V$ rate of pressure rise.

*Significant difference $(p<0.01)$ from $2 \mathrm{~V}$-C.

$\nmid$ Significant difference $(p<0.01)$ from 1V-HD.

coronary flow increased by approximately $20 \%$ at 40 minutes of continuous hemodilution and decreased similarly thereafter (Fig. 3, $A$ ). LAD coronary flow responded significantly differently to continuous hemodilution in the two groups: LAD flow decreased sharply after 40 minutes of hemodilution in the $2 \mathrm{~V}$-HD group, whereas a marked increase in LAD flow was observed in the $1 \mathrm{~V}$-HD group during the first 70 minutes of hemodilution (Fig. 3, $B$ ). Systolic segment shortening in the LC territory decreased similarly in the $\mathrm{V}$-HD and the $2 \mathrm{~V}$-HD groups (Fig. 3, A). Systolic segment shortening in the LAD territory, however, responded differently to a marked degree in the $1 \mathrm{~V}$-HD and the 2V-HD groups. Although systolic shortening in the LAD territory started to decrease at approximately 40 minutes of continuous hemodilution in the 2V-HD group, an increase was observed at that time in the IV-HD group, reaching a maximum $(+50 \%)$ at approximately 60 minutes (Fig. $4, B$ ); subsequently, systolic shortening in the LAD territory started to decrease. The response of systolic segment shortening in the RV free wall to progressive hemodilution was significantly better preserved in the 1V-HD group than in the 2V-HD group (Fig. 4, C).

Responses of global cardiovascular functions to continuous hemodilution. Mean arterial and coronary perfusion pressures (Fig. 5, $A$ and $B$ ), maximum positive and maximum negative $\mathrm{LV}$ rate of pressure rise, as well as maximum positive and maximum negative $R V$ rate of pressure rise, were all better preserved in the $1 \mathrm{~V}-\mathrm{HD}$ group than in the $2 \mathrm{~V}$-HD group during progressive hemodilution (Fig. 6, $A$ to $D$ ).

\section{Discussion}

The results of the present study demonstrate that (1) moderate hemodilution (hemoglobin $>9 \mathrm{gm} / \mathrm{dl}$ ) is relatively well tolerated by dogs with single $\mathrm{LC}$ stenosis and by dogs with proximal LAD and proximal LC coronary stenoses, (2) advanced hemodilution beyond $9 \mathrm{gm} / \mathrm{dl}$ is better tolerated by dogs with single LC stenosis than by dogs with proximal LAD and proximal LC coronary stenoses, and (3) the reduced hemodilution tolerance in the presence of proximal LAD and proximal LC stenoses 


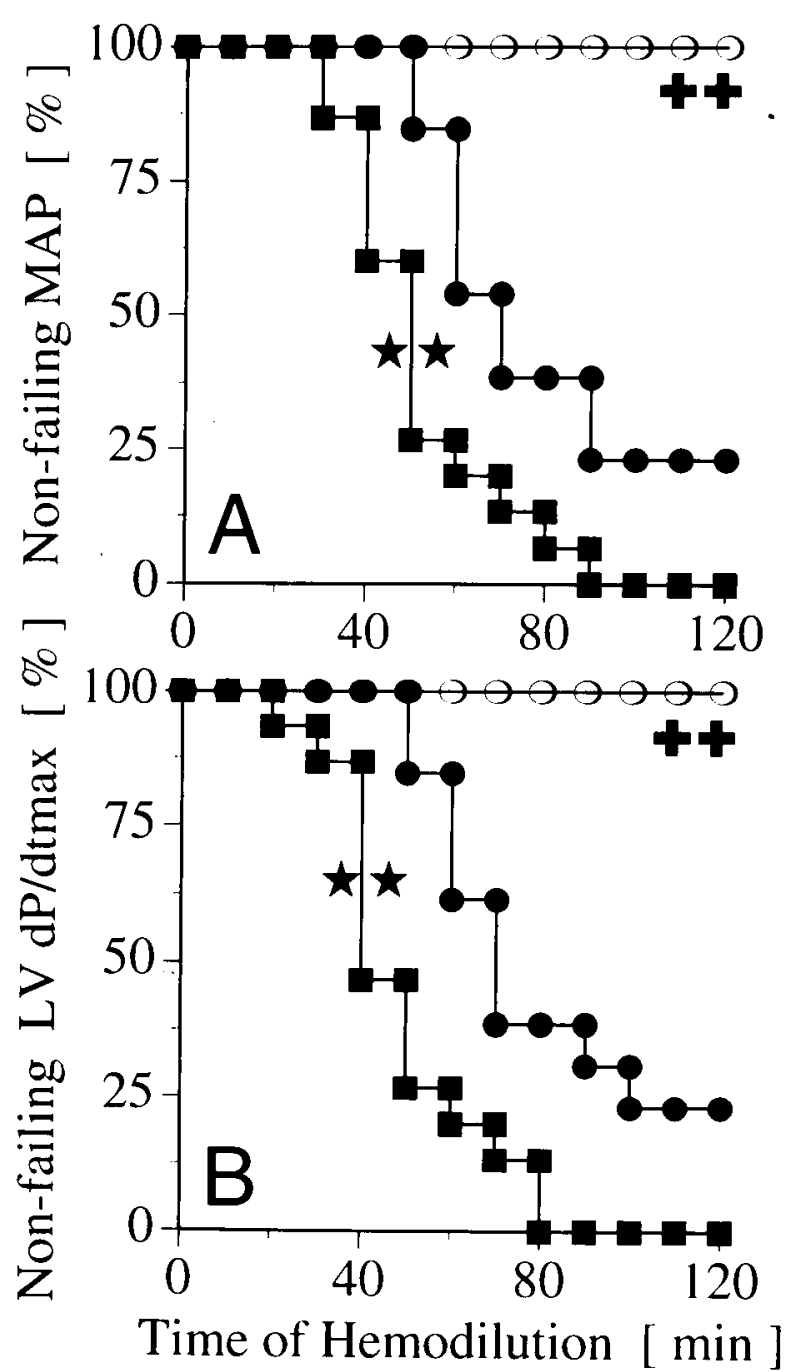

Fig. 2. A, Nonfailing mean arterial pressure $(M A P)$; $\mathbf{B}$, nonfailing maximum positive $\mathrm{LV}$ rate of pressure rise $(L V d P / d t-$ max) during continuous progressive hemodilution. For other abbreviations, see Fig. 1.

al hemoglobin with respect to time in both hemodiluted groups. Thus, time of hemodilution can be regarded as synonymous with the degree of normovolemic hemodilution; this is of particular importance because animals with proximal LAD and proximal LC coronary stenoses failed quickly once hemodiluted beyond the individual threshold of hemodilution tolerance. Even with a 10-minute data sampling frequency, it was not uncommon to observe only moderate dysfunction at one data collection time and death within the next 10 minutes. Because the decrease in arterial hemoglobin over time was similar in both hemodiluted groups, time of hemodilution is regarded as a valid indicator of the stage of hemodilution. 


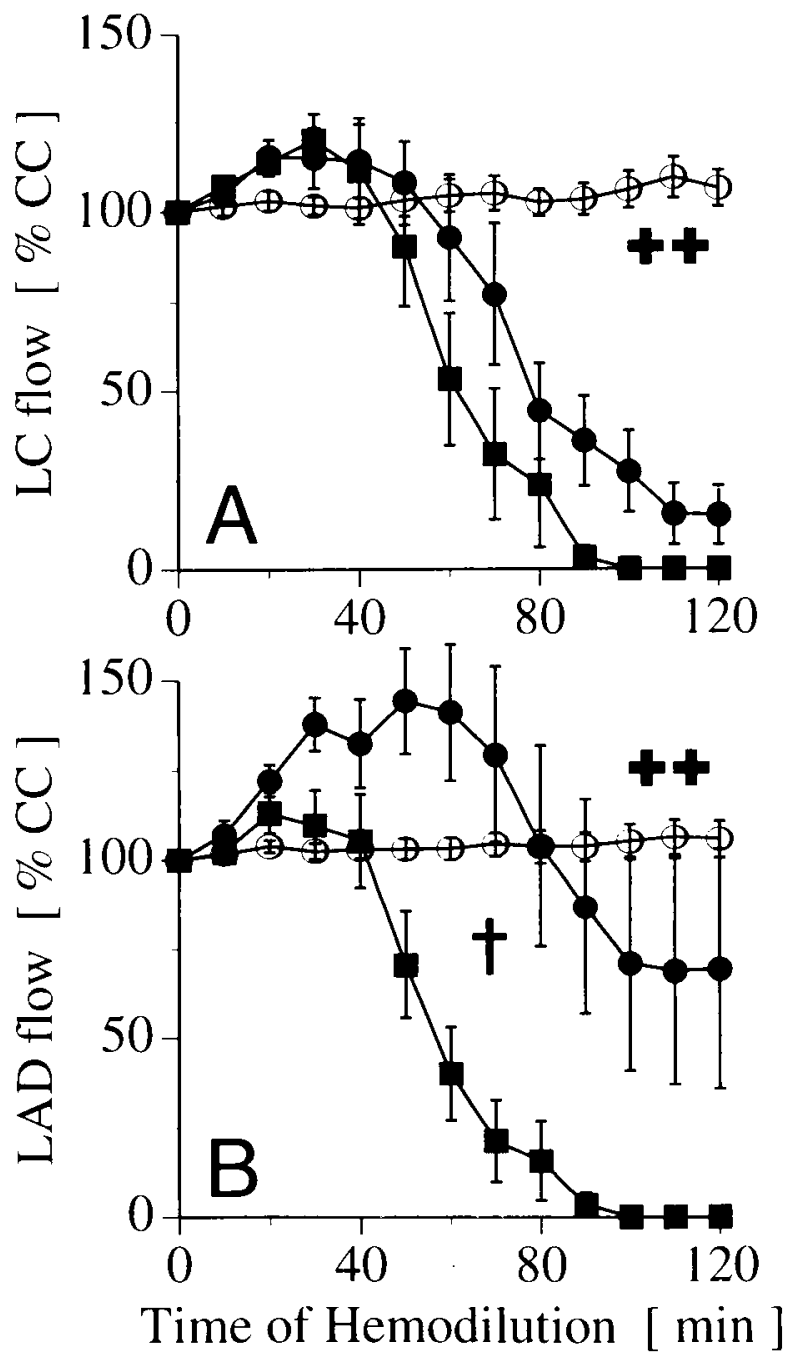

Fig. 3. A, LC flow in percentage of $L C$ flow measured at critical constriction $(C C)$; $\mathbf{B}$, LAD flow in percentage of LAD flow measured at $\mathrm{CC}$ during continuous progressive hemodilution. †Significantly different response $(p=0.0528)$ between both hemodiluted groups. For other abbreviations, see Fig. 1.

Physiologic failure criteria were defined as death of the animal or a $50 \%$ decrease in function (as compared with critical constriction) of systolic segment shortening in the LC and LAD territories, mean arterial pressure, or maximum positive $\mathrm{LV}$ rate of pressure rise. These failure criteria were below the lower confidence limits of all analyzed parameters in the control animals and were never achieved by any control animal during the 2-hour observation period. A $50 \%$ or greater decrease in function or death of the animal therefore indicates significant hemodilution-induced dysfunction.

Physiologic findings. Moderate hemodilution (hemoglobin $>9 \mathrm{gm} / \mathrm{dl}$ ) is relatively well tolerated by dogs with
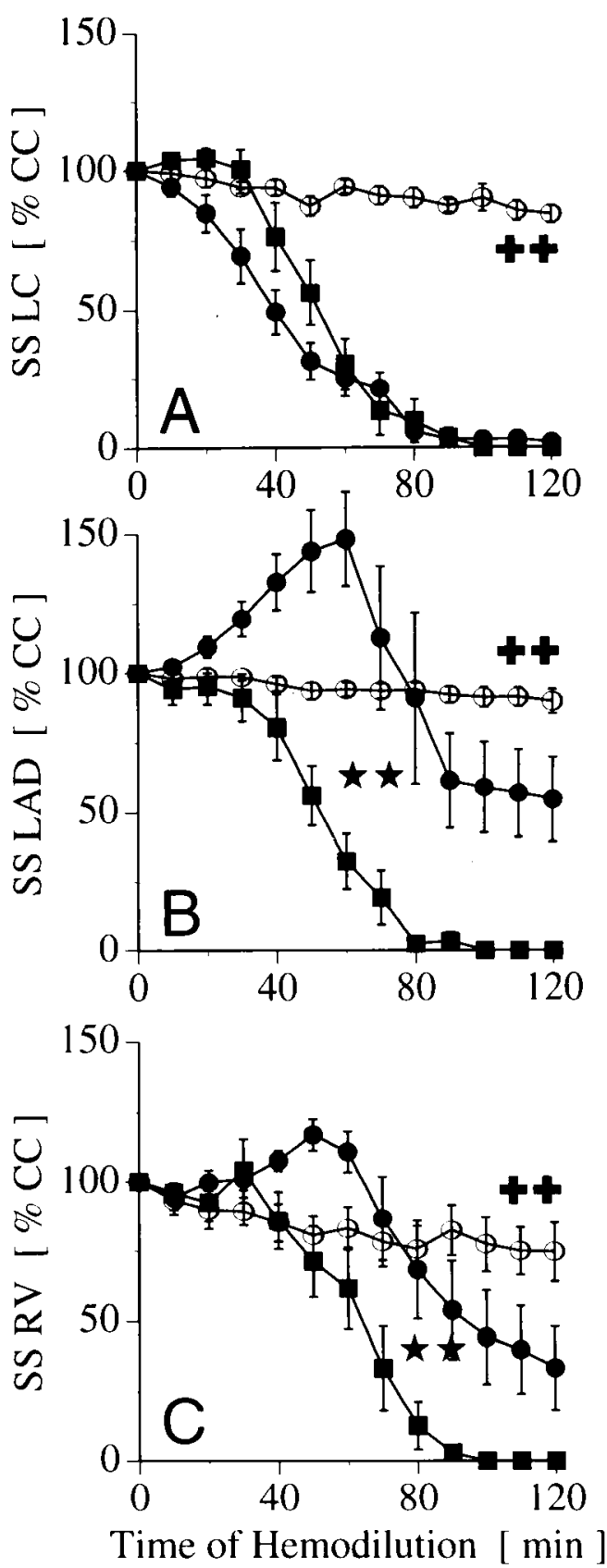

Fig. 4. A, Systolic shortening in the LC territory ( $S S L C$ ) in percentage of SS LC measured at critical constriction $(C C)$; $\mathbf{B}$, systolic shortening in the LAD territory $(S S L A D)$ in percentage of SS LAD measured at $\mathrm{CC}$; $\mathrm{C}$, systolic shortening in the $\mathrm{RV}$ free wall (SS RV) in percentage of SS RV measured at CC during continuous progressive hemodilution. For other abbreviations, see Fig. 1.

single LC stenosis and by dogs with proximal LAD and proximal LC coronary stenoses. In the first 30 minutes of continuous hemodilution, the hemoglobin decreased from approximately $13.7 \mathrm{gm} / \mathrm{dl}$ (Table II) to approximately 9 
$\mathrm{gm} / \mathrm{dl}$. Despite this decrease in hemoglobin, failure criteria were only reached once for systolic shortening in the LAD-supplied LV myocardium: once for systolic shortening in the LC-supplied LV myocardium and once for maximum positive $\mathrm{LV}$ rate of pressure rise in a total of 28 hemodiluted animals (Figs. 1 and 2). Also, global cardiovascular and regional $R V$ and LV myocardial contractile functions were well preserved at 30 minutes of hemodilution compared with critical constriction (Figs. 3 to 6). Only systolic shortening in the LC-supplied LV posterior wall was moderately reduced to $70 \%$ compared with critical constriction in animals with a single LC stenosis, whereas systolic contractile function in the LV posterior wall was fully preserved at 30 minutes of hemodilution in animals with proximal LAD and proximal LC stenoses (Fig. 4).

Tolerance to advanced hemodilution (hemoglobin $<9$ $\mathrm{gm} / \mathrm{dl}$ ), however, was significantly better in dogs with single-vessel coronary stenosis (proximal LC stenosis only) compared with animals with proximal LAD and proximal LC stenoses. This tolerance is evidenced by a longer time to failure (Figs. 1 and 2 ) and by an improved preservation of global cardiovascular and regional myocardial functions during progressive hemodilution (Figs. 3 to 6 ). The better global cardiovascular stability of the single coronary artery stenosis group may be due to the compensatory increase in regional myocardial contractile function in the noncompromised LAD territory (Fig. 4).

An increase in myocardial contractile function in noncompromised myocardium has been observed in two previous hemodilution studies in dogs with isolated LAD stenosis, ${ }^{1,2}$ as well as in several forms of experimental ${ }^{7-9}$ and clinical regional myocardial contractile failure. ${ }^{10,11}$ The true significance of the compensatory increase in noncompromised myocardial contractile function, however, could not be determined in the previous hemodilution studies with single LAD stenosis because only mild global cardiovascular dysfunction was achieved. ${ }^{1,2}$ In the present study, hemodilution was continued to induce severe global LV dysfunction. With single-vessel stenosis, failure of regional contractile function occurred far earlier than did global cardiovascular failure, as evidenced by the preservation of $L V$ rate of pressure rise and mean arterial pressure until a significantly later time period during hemodilution. By contrast, with multivessel stenoses, global cardiovascular collapse coincided with failure of regional contractile function. Enhanced contractile function of the noncoronary flow-compromised anterior apical myocardium appears to compensate for the contractile dysfunction of the coronary flow-compromised posterior myocardium, which illustrates the significance of coronary disease in determining the extent of the normovolemic hemo-

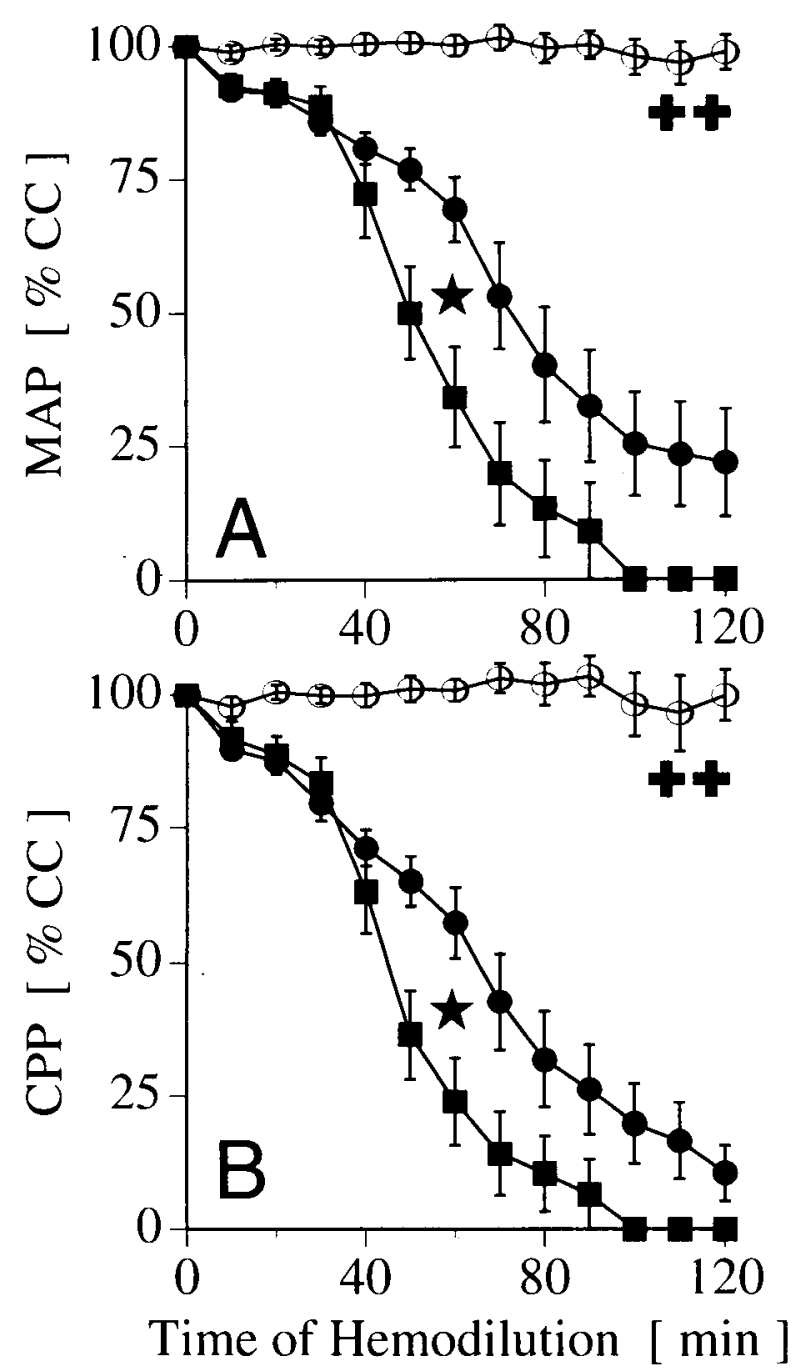

Fig. 5. A, Mean arterial pressure $(M A P)$ in percentage of MAP measured at critical constriction $(C C)$; $\mathbf{B}$, coronary perfusion pressure (CPP) in percentage of CPP measured at $\mathrm{CC}$ during continuous progressive hemodilution. *Significantly different response $(p<0.05)$ between both hemodiluted groups. For other abbreviations, see Fig. 1.

dilution that can be tolerated by the cardiovascular system.

The mechanisms involved in the compensatory increase in myocardial contractile function during hemodilution-induced LC territory failure are not entirely clear. Systolic segment shortening does not increase during normovolemic hemodilution in dogs with normal coronary arteries. ${ }^{12}$ Therefore, an increase in regional myocardial contractile function in a noncompromised LV territory during normovolemic hemodilution and hemodilution-induced contractile dysfunction in a remote, coronary flow-compromised LV territory is a compensatory mechanism rather than a mechanism that is inherent to 

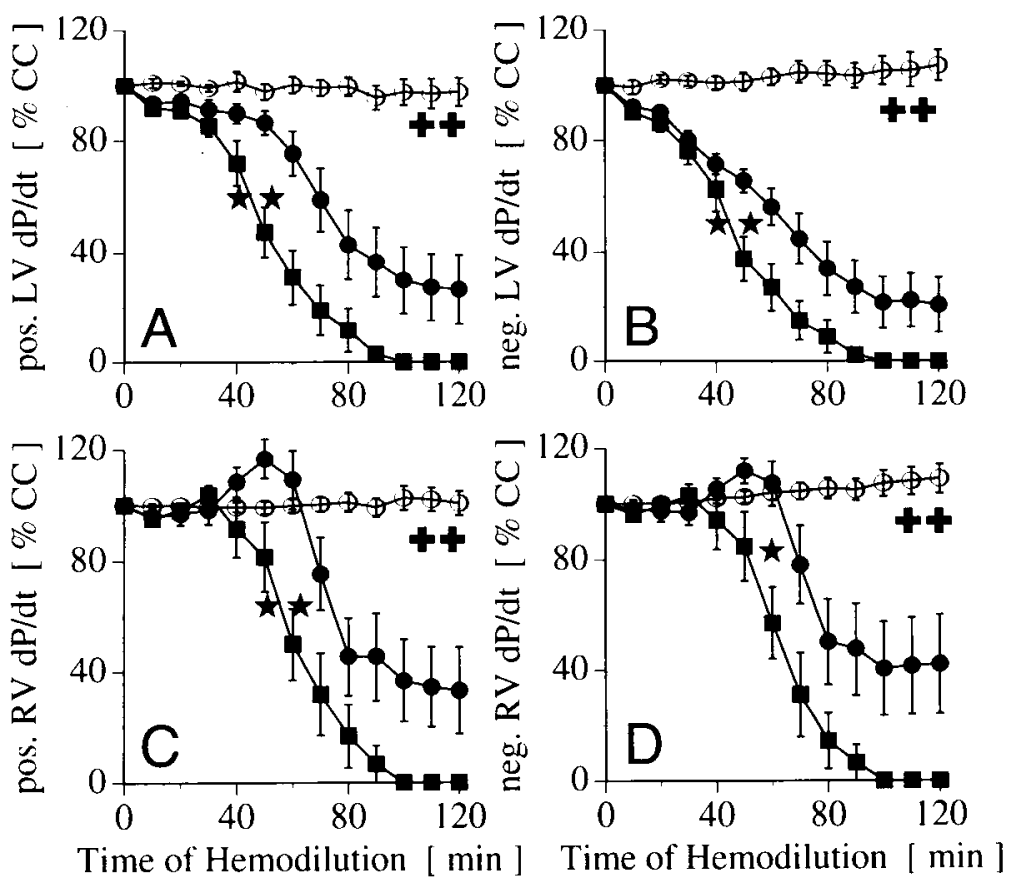

Fig. 6. A, Maximum positive $\mathrm{LV}$ rate of pressure rise (pos. $L V d P / d t$ ) in percentage of pos. $\mathrm{LV} \mathrm{dP} / \mathrm{dt}$ measured at critical constriction $(C C)$; B, maximum negative $\mathrm{LV} \mathrm{dP} / \mathrm{dt}($ neg. $L V d P / d t)$ in percentage of neg. $\mathrm{LV} \mathrm{dP} / \mathrm{dt}$ measured at $\mathrm{CC} ; \mathrm{C}$, maximum positive $\mathrm{RV} \mathrm{dP} / \mathrm{dt}$ (pos. $R V d P / d t$ ) in percentage of pos. $\mathrm{RV} \mathrm{dP} / \mathrm{dt}$ measured at $\mathrm{CC} ; \mathbf{D}$, maximum negative $\mathrm{RV} \mathrm{dP} / \mathrm{dt}$ (neg. $R V d P / d t$ ) in percentage of neg. $\mathrm{RV} \mathrm{dP} / \mathrm{dt}$ measured at $\mathrm{CC}$ during continuous progressive hemodilution. $\star$ Significantly different response $(p<0.05)$ between both hemodiluted groups. For other abbreviations, see Fig. 1.

hemodilution per se. End-diastolic dimensions are variably reported to increase ${ }^{4,8}$ in the compensating LV territory and be unchanged during remote contractile failure. $^{1,2,9,11}$ A regional mechanism according to the Starling principle thus may be involved but may not explain the compensatory increase in myocardial contractile function in noncompromised LV myocardium entirely. In the present study, end-diastolic segment length in the LAD territory increased slightly by $3 \%$ at 30 minutes and by $7 \%$ at 60 minutes of hemodilution in the single-vessel coronary stenosis group when systolic shortening was increased by approximately $20 \%$ and $50 \%$, respectively (Fig. 4), which demonstrates that increased regional preload is unlikely the sole mechanism involved in the compensatory mechanism. An increase in endogenous catecholamines, observed during progressive hemodilution, ${ }^{12}$ may also contribute to the compensatory increase in regional myocardial contraction. Further studies are necessary to elucidate the exact mechanisms involved in the compensatory increase in contractile function during hemodilution-induced contractile failure. . RV function was well preserved during the initial 40 minutes of hemodilution (Figs. 4 and 6). During the sub- sequent hemodilution period (50 to 120 minutes of hemodilution) global RV contractile function as assessed by maximum positive and maximum negative $R V$ rate of pressure rise (Fig. 6), as well as myocardial contractile function in the RV free wall (Fig. 4), was better preserved in animals with a single-vessel coronary artery stenosis than in animals with multivessel coronary stenoses. This difference may be due to the canine coronary anatomy because parts of the interventricular septum, as well as those of the free anterior RV wall, are perfused by the LAD, ${ }^{1,13}$ Thus RV tolerance to normovolemic hemodilution may be expected to be diminished with compromised LAD blood flow, as was observed in animals with multivessel coronary stenoses (Fig. 4). Alternatively, RV free wall dysfunction could have resulted from diminished coronary perfusion pressure; the period when RV dysfunction first appeared coincides with significant decrements in coronary perfusion pressure in animals with multivessel coronary stenoses. Data of the present study do not allow differentiation of which of the previously mentioned mechanisms, the presence of the LAD stenosis or the more exaggerated decrease in right coronary perfusion pressure, is more relevant for the reduced 
hemodilution tolerance in the animals with multivessel coronary stenoses.

It can only be speculated why systolic shortening in the LAD-perfused and LC-perfused LV myocardium or maximum positive $\mathrm{LV}$ rate of pressure rise each failed before 30 minutes of hemodilution in separate dogs. Hemoglobin decreased slightly faster in these dogs, resulting in hemoglobin values at failure of $10 \mathrm{gm} / \mathrm{dl}(10$ minutes) and $8.6 \mathrm{gm} / \mathrm{dl}$ and $10.8 \mathrm{gm} / \mathrm{dl}$ (20 minutes). Because a certain variability to progressive isovolemic hemodilution is known in this canine model of acute coronary stenosis, ${ }^{2}$ these occasional early failures do not contradict the conclusion that, in general, moderate hemodilution (hemoglobin $>9 \mathrm{gm} / \mathrm{dl}$ ) is well tolerated by dogs with single LC stenosis as well as by dogs with proximal LAD and proximal LC coronary stenoses.

Extrapolating these findings to the clinical situation can be done only with great caution. The present data, however, indicate that moderate normovolemic hemodilution (hemoglobin $<9 \mathrm{gm} / \mathrm{dl}$ ) is relatively well tolerated in the presence of single-vessel and multivessel coronary stenoses. Tolerance to hemodilution beyond this relatively moderate level, however, may crucially depend on the compensatory increase in myocardial contractile function in non-coronary flow-compromised myocardium.

Tolerance to progressive normovolemic hemodilution was compared between dogs with a single proximal LC stenosis and dogs with proximal LAD and proximal LC coronary stenoses. Moderate normovolemic hemodilution (hemoglobin $>9 \mathrm{gm} / \mathrm{dl}$ ) was relatively well tolerated by both groups. Advanced normovolemic hemodilution, however, was better tolerated by dogs with single LC stenosis. This tolerance is evidenced by a longer time to failure and an improved preservation of global cardiovascular and regional myocardial functions during progressive hemodilution. The better hemodilution tolerance in the LC stenosis group may be explained by the compensatory increase in myocardial contractile function in noncoronary flow-compromised myocardium, which appears to be crucial for global cardiovascular stability during hemodilution in the presence of coronary stenoses.

\section{REFER EN CES}

1. Spahn DR, Smith LR, McRae RL, Leone BJ. Effects of acute isovolemic hemodilution and anesthesia on regional function in left ventricular myocardium with compromised coronary blood flow. Acta Anaesth Scand 1992;36:62836.

2. Spahn DR, Smith RL, Veronee CD, et al. Acute isovolemic hemodilution and blood transfusion: effects on regional function and metabolism in myocardium with compromised coronary blood flow. J THORAC CARDiovasc SURG 1993;105:694-704.

3. Bugge-Asperheim B, Leraand S, Kiil F. Local dimensional changes of the myocardium measured by ultrasonic technique. Scand J Clin Lab Invest 1969;24:361-71.

4. Theroux P, Franklin D, Ross J, Kemper WS. Regional myocardial function during acute coronary artery occlusion and its modification by pharmacological agents in the dog. Circ Res 1974;35:896-906.

5. Leone BJ, Philbin DM, Lehot JJ, Foëx P, Ryder WA. Gradual or abrupt nitrous oxide administration in a canine model of critical coronary stenosis induces regional myocardial dysfunction that is worsened by halothane. Anesth Analg 1988;67:814-22.

6. Lowenstein E, Foëx P, Francis M, Davies WL, Yusuf S, Ryder WA. Regional ischemic ventricular dysfunction in myocardium supplied by a narrowed coronary artery with increasing halothane concentration in the dog. Anesthesiology 1981;55:349-59.

7. Beyersdorf F, Acar C, Buckberg GD, et al. Studies on prolonged acute regional ischemia. III. Early natural history of simulated single and multivessel disease with emphasis on remote myocardium. J THORAC CARDIOVASC SuRg 1989; 98:368-80.

8. Mattrey RF, Slutsky RA, Long SA, Higgins CB. In vivo assessment of left ventricular wall and chamber dynamics during transient myocardial ischemia using prospectively ECG-gated computerized transmission tomography. Circulation 1983;67:1245-51.

9. Molaug M, Geiran O, Kiil F. Compensatory cardiac mechanisms evoked by septal ischemia in dogs. Am J Cardiol 1983;51:201-6.

10. Schmidt WG, Sheehan FH, von Essen R, Uebis R, Effert $S$. Evolution of left ventricular function after intracoronary thrombolysis for acute myocardial infarction. Am J Cardiol 1989;63:497-502.

11. Rigaud M, Rocha P, Boschat J, Farcot JC, Bardet J, Bourdarias JP. Regional left ventricular function assessed by contrast angiography in acute myocardial infarction. Circulation 1979;60:130-9.

12. Bowens C, Spahn DR, Smith LR, et al. Hemodynamic effects of acute, extended isovolemic hemodilution. Anesth Analg 1993;76:1027-32.

13. Bertho E, Gagnon G. A comparative study in three dimensions of the blood supply of the normal interventricular septum in human, canine, bovine, porcine, ovine and equine heart. Dis Chest 1964;46:251-62. 